\title{
TU/e EmonOWEN

\section{Enhanced feeds in focal plane imaging array systems: off focus configurations}

\section{Citation for published version (APA):}

Bonnedal, M., Neto, A., Llombart, N., Gerini, G., \& de Maagt, P. J. I. (2007). Enhanced feeds in focal plane imaging array systems: off focus configurations. In Proceedings of European Microwave Conference, 2007, Munich, 8-10 Oct. 2007 (pp. 253-256). Institute of Electrical and Electronics Engineers. https://doi.org/10.1109/ECWT.2007.4403994

DOI:

10.1109/ECWT.2007.4403994

Document status and date:

Published: 01/01/2007

\section{Document Version:}

Publisher's PDF, also known as Version of Record (includes final page, issue and volume numbers)

\section{Please check the document version of this publication:}

- A submitted manuscript is the version of the article upon submission and before peer-review. There can be important differences between the submitted version and the official published version of record. People interested in the research are advised to contact the author for the final version of the publication, or visit the $\mathrm{DOI}$ to the publisher's website.

- The final author version and the galley proof are versions of the publication after peer review.

- The final published version features the final layout of the paper including the volume, issue and page numbers.

Link to publication

\section{General rights}

Copyright and moral rights for the publications made accessible in the public portal are retained by the authors and/or other copyright owners and it is a condition of accessing publications that users recognise and abide by the legal requirements associated with these rights.

- Users may download and print one copy of any publication from the public portal for the purpose of private study or research.

- You may not further distribute the material or use it for any profit-making activity or commercial gain

- You may freely distribute the URL identifying the publication in the public portal.

If the publication is distributed under the terms of Article 25fa of the Dutch Copyright Act, indicated by the "Taverne" license above, please follow below link for the End User Agreement:

www.tue.nl/taverne

Take down policy

If you believe that this document breaches copyright please contact us at:

openaccess@tue.nl

providing details and we will investigate your claim. 


\title{
Enhanced Feeds in Focal Plane Imaging Array Systems: Off Focus Configurations
}

\author{
M. Bonnedal ${ }^{* 1}$, N. Llombart ${ }^{\# 2}$, A. Neto ${ }^{\# 3}$, G. Gerini ${ }^{\# 4}$, P. De Maagt ${ }^{+5}$ \\ * Saab Space \\ Gothenburg, Sweden \\ ${ }^{1}$ magnus.bonnedalespace.se \\ \# TNO Defence, Security and Safety \\ Oude Waalsdorperweg 63, 2597 AK The Hague, The Netherlands \\ ${ }^{2}$ nuria.llombartjuandtno.nl \\ 3 andrea.neto@tno.nl \\ ${ }^{4}$ giampiero.gerini@tno.nl \\ ${ }^{+}$ESTEC, European Space Agency \\ PO Box 299, NL 2200 AG Noordwijk, The Netherlands \\ ${ }^{5}$ peter.de.maagt@esa.int
}

\begin{abstract}
The performances of focal plane arrays that implement multi-beam coverage from a single reflector antenna are usually reduced by conflicting requirements on the feed elements. Dense packing is required to minimize the beam separation, while typically large apertures provide the high feed directivity which in turn translates in low spill over losses from the reflector. In this paper the use of a dielectric super-layer is proposed to shape the radiation pattern of each feed so that the spill over from the reflector is reduced without increasing the dimensions of each aperture. A prototype with 19 wave-guides arranged in a hexagonal lattice has been designed. The simulated embedded patterns provide an increase of the edge of coverage gain, with respect to the free space case, of at least $1 \mathrm{~dB}$ in an operating bandwidth of $\approx 6 \%$. Moreover when a frequency and polarization reuse scheme is adopted the increase in the edge of coverage is 2.1 dB leading to a fully efficient use of the reflector.
\end{abstract}

\section{INTRODUCTION}

Present and next generation telecommunication satellite systems often require multiple beam capability. The three fundamental ways to achieve high coverage gain are overlapping feed arrays with expensive feed networks, interleaved beams with multiple apertures, and designs with a single aperture and a single feed per beam [1]. This last approach requires small aperture feeds in order to obtain a small beam separation, however these small feeds have low gain which results in 2 or $3 \mathrm{~dB}$ of power lost in spill over from the reflector. For this reason this approach is usually not adopted for the military [1] or commercial telecommunication satellite systems. This paper specifically addresses and solves this problem.

G. V. Trentini [2] was the first to propose the use of a partially reflecting screen to increase the directivity of single aperture. A point source would generate an ensemble of waves that impinge on a screen that is partially reflective and partially transmitting. The reflected rays propagate laterally and then are redirected toward the partially reflecting screen, so that overall they generate a unique wave that mainly radiates in the broadside direction. Since then this technique has been proposed in many other configurations characterized by periodic super-layers realized in dielectric or metal materials [3]-[4]. In these papers the fact that the enhancement in gain is due to the excitation of leaky waves has been clarified. Unfortunately most of these attempts were characterized by narrow frequency bandwidths $(\mathrm{BW})$ that are not suited for broad band or even moderate band scenarios. Most recently, [5] studied the compromise between bandwidth and directivity for printed antennas and arrays in the presence of periodic super-layers.

In the present contribution leaky waves are used in order to enhance the performances of each of the small feeds used in an array for multi beam reflector systems. The spill over is targeted and significantly reduced. Since the enhancement of multi-beam antenna performances is a basic need for realistic next generation telecom systems but also for imaging arrays in the $\mathrm{mm}$ and sub-mm wave regimes, two prototypes have been built. The first one is of general applicability and assumes a worst case scenario with significant coupling between neighboring radiators. The second one focuses on a specific satellite telecommunication scenario and there the trade offs between the BW, the isolation of the beams and the efficiency drives the electrical design.

\section{System Parameters AND REFEREnCE ARRAY}

The generic scenario introduced in this section involves an area to be covered by independent beams, arranged in an hexagonal lattice and separated by an angle $\Delta \theta$. To achieve this coverage a corresponding hexagonal array placed in the focal plane of a Cassegrain off focus parabolic reflector is considered, as shown in Fig. 1. The array elements are designed to be compatible with circular polarization in order to maintain the highest usability. The basic parameters characterizing an imaging system are: the beam separation $\Delta \theta$, the reflector diameter, $D$, and the focal distance, $F$ (see Fig. 1). $F / D$ defines the subtended angle $\theta_{s u b}$. All the power that is 


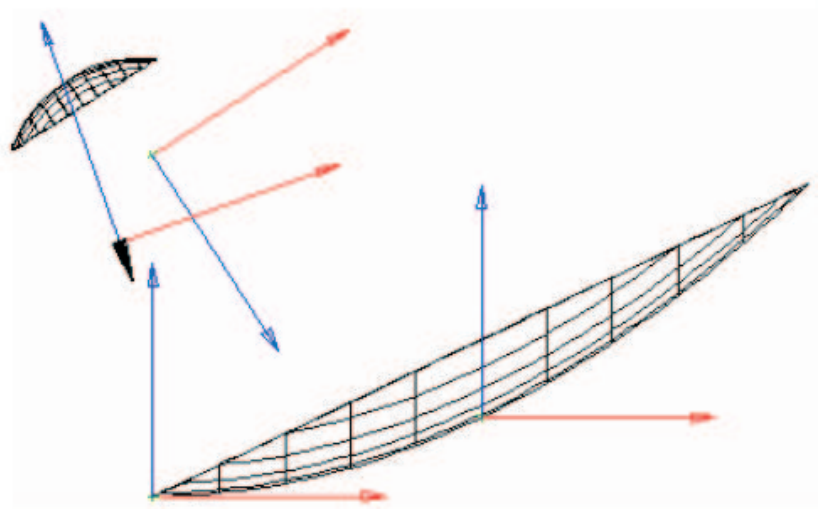

Fig. 1. Schematic view of a reflector configuration

launched by the feed but is not intercepted by the reflector is effectively lost for the system (spill over). In order to enhance the spill over efficiency one would like to use directive feeds, however the dimensions of the apertures are limited by the period. For this reason most imaging systems need to perform a trade off between the efficiency with which each element of the array excites the reflector and the capacity to sample the available field of view. In the following sections a single dielectric super-layer will be proposed to allow the overlap of equivalent apertures.

In order to establish a reference to which compare the performances of the leaky wave enhanced arrays, a standard waveguide array is investigated first, Fig. 2(a). It consists of an hexagonal grid array composed of 19 circular waveguide horns that open in an finite ground plane of dimensions $\left(12 \lambda_{0} \times 12 \lambda_{0}\right)$. To accurately evaluate the performances of a reflector system fed by this reference array, the secondary patterns are obtained resorting to a complete Grasp analysis starting from the fields radiated by the reference array, which in turn have been calculated using CST Microwave Studio. The key merit parameter for these multi-beam systems is the edge of coverage gain, which is defined at the cross over between three adjacent beams: $G_{e o c}=G(\Delta \theta / \sqrt{3})$. Figure 2(b) shows the edge of coverage gain for a reflector that provides $\Delta \theta \approx 1^{\circ}$, which corresponds to $F \approx 66.66 \lambda_{0}$.

\section{Waveguide ARray Prototypes}

When the distance between a dielectric super-layer and a ground plane is about half of a free space wavelength, leaky waves can propagate between the sandwiched area. The enhancement of the broadside directivity of a single antenna is obtained when the super-layer thickness is a quarter of the dielectric wavelength [6]. The proposed prototype is shown Fig. 3(a). The array is composed, like the reference array, by 19 waveguides, this time of square cross section with width, $w=0.67 \lambda_{0}$, and separation $d=1.2 \lambda_{0}$. Note that in this case the array of apertures does not fully occupy the central part of the ground plane. The dielectric constant of the slab is

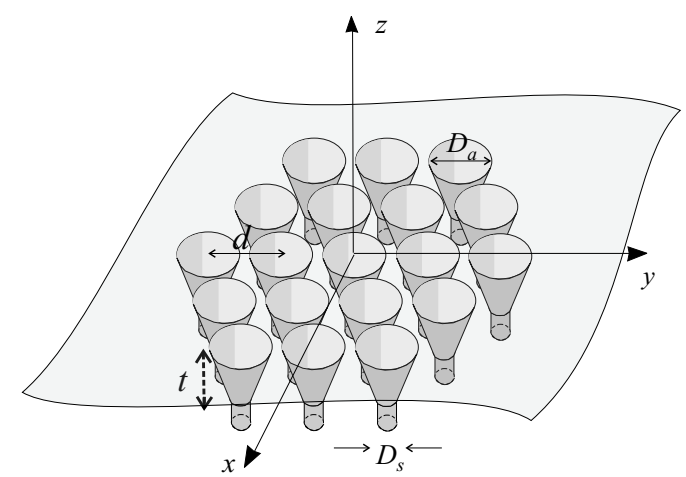

(a)

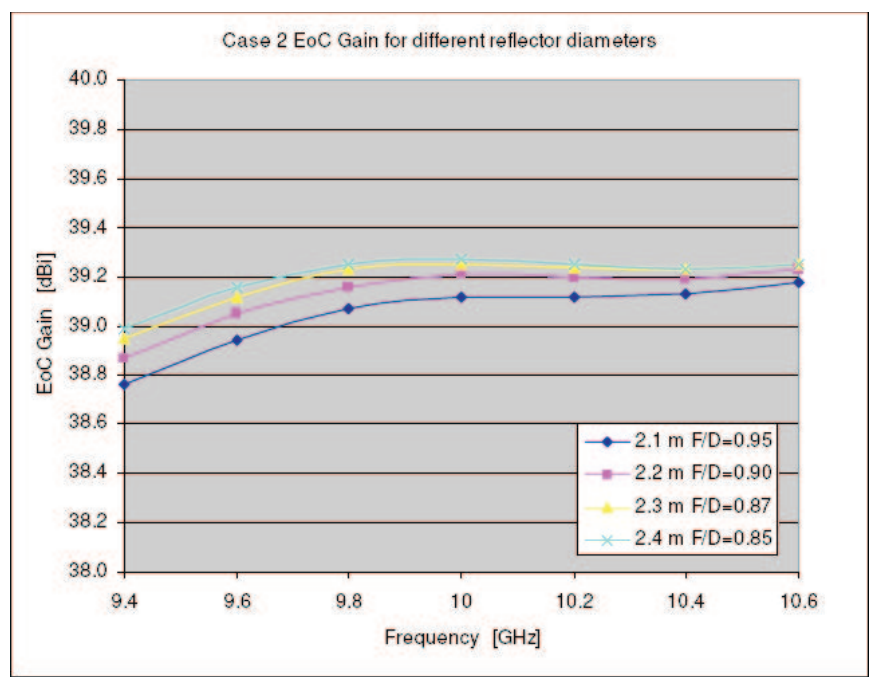

(b)

Fig. 2. (a) Hexagonal grid array with periodicity $d=1.2 \lambda_{0}$ of circular metallic waveguide $D_{s}$ opening in a infinitely extended ground plane. The apertures $D_{a}=1.1 \lambda_{0}$ fully sample the array. (b) Edge of coverage gain as a function of the frequency.

4.5. In this kind of super-layer structures, there is a TM leaky wave pointing to large angles that could contribute to spill over losses. In order to cancel its contribution, it is convenient to load the waveguide with a double irises configuration. polarization by properly phase shifting the two polarizations. The two slots are excited in phase and located at distance such that their contributions cancel out exactly at the pointing angle of this leaky wave. Each of the couples of slots is associated to one polarization so that each waveguide can be operated in circular polarization by properly phase shifting the two polarizations. The slots are shaped as an arc of a circle in order to achieve the desired cancellation over the maximum azimuthal angle, [7].

The impact of the mutual coupling on the radiation patterns 


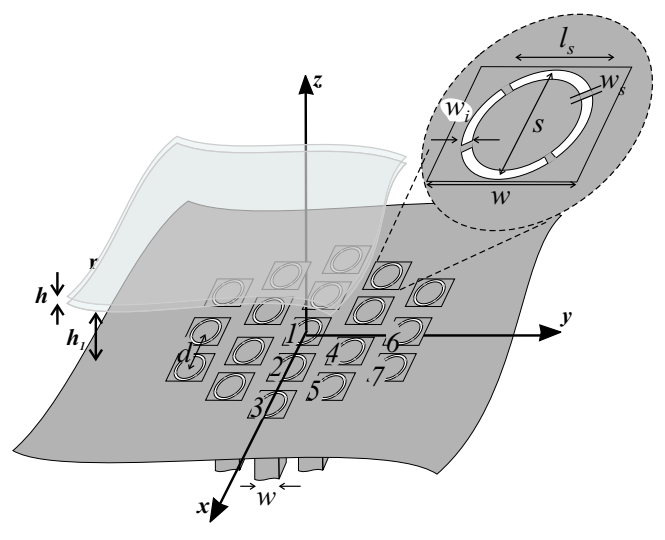

(a)

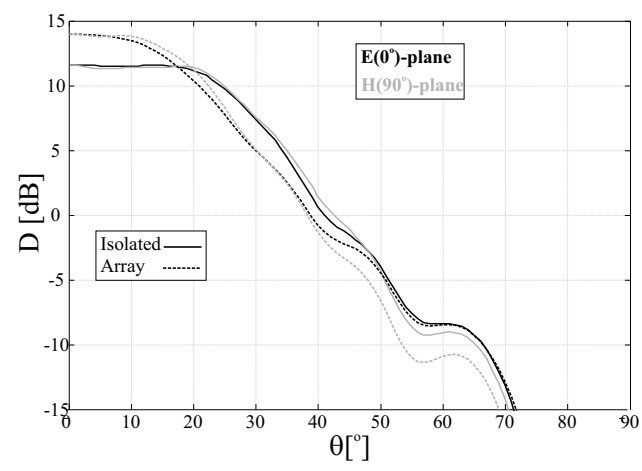

(b)

Fig. 3. (a) Prototype waveguide array. The area of each unit cell is significantly larger than the dimension of each waveguide. (b) Amplitude of the calculated radiation patterns.

can be seen in Fig. 3(b). The calculated patterns are shown for the embedded and the isolated cases. The maximum directivity in the array environment is lower than the one obtained in isolation. That is because the distance between the array elements is such that the scattered field from the neighboring waveguides contributes almost out of phase with respect to the central element at broadside. While the embedded patterns are representative of the worst case scenario, the isolated patterns, in first approximation, can be representative of an ideal case, in which the adjacent waveguides are loaded with properly tuned reactive loads to create an equivalent ground plane on the apertures.

\section{A. Worst Case Scenario}

The worst case scenario corresponds to an imaging configuration in which the isolation between beams associated to adjacent wave-guides is not a driving parameters. For instance in radiometry at $\mathrm{mm}$ or sub-mm waves. Here all the neighboring wave-guides are closed in matched loads

A parametric study of the $G_{e o c}$ equivalent to of the reference array is plotted in Fig. 4. For all three $F / D$ the gain presents a weak frequency dependence. It is apparent that there is a significant improvement that can be as high as $1.7 \mathrm{~dB}$ for $F / D=0.67$.

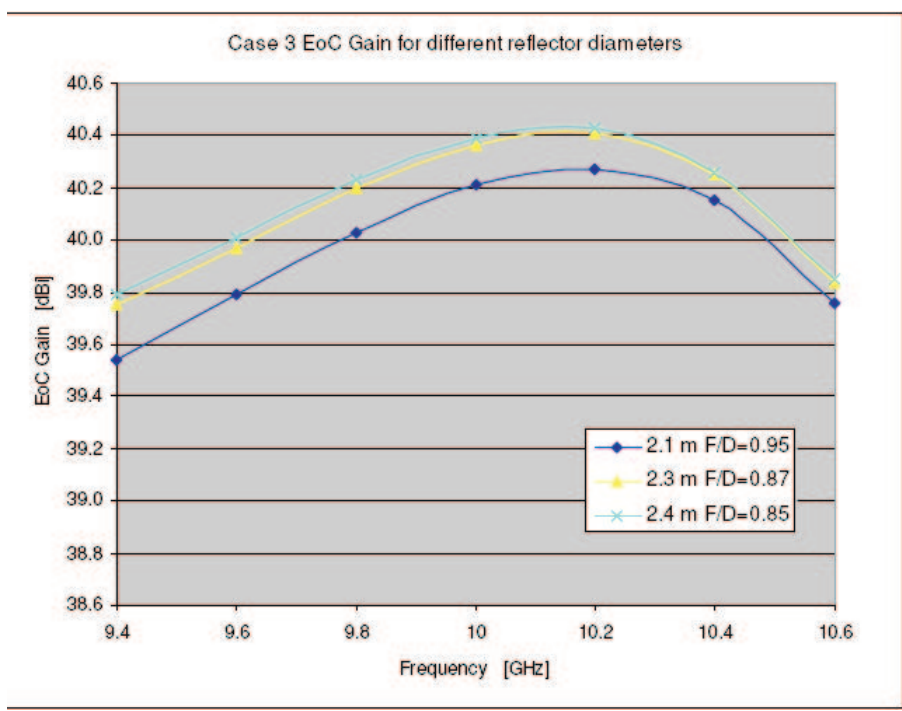

Fig. 4. Edge of coverage gain calculated from the simulated patterns for the worst case scenario.

\section{B. Best Case Scenario}

For the best case a satellite based telecommunication scenario, in Ka band which makes use of two frequency bands and two linear polarizations to obtain independent, interleaved beams (separated by $1^{\circ}$ ) is imagined. The implementation of interleaved beams and of single aperture corresponding focal plane array is based on a 4 channel reuse scheme (see Fig. 5), with two linear polarizations (performed at the iris level) and two frequencies. The distance of the frequency filter from the aperture is tuned to achieve an effective short circuit at the aperture. For budget reasons and thanks to the smooth behavior as a function of the frequency of the phase of the reflection coefficient of the frequency filter, the reactive load can be assumed to be represented by a piece of waveguide loaded at a certain distance by a real short circuit.

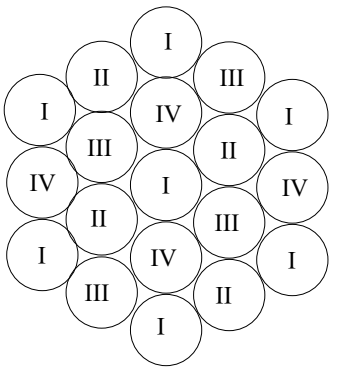

Fig. 5. Frequency and polarization re-use scheme. $I \rightarrow c o / f_{1} ; I I \rightarrow$ $c o / f_{2} ; I I I \rightarrow c x / f_{1} ; I V \rightarrow c x / f_{2}$. 
The increase in edge of coverage in this second scenario (see Fig. 6) is as high as $2.2 \mathrm{~dB}$, which essentially means that the no power is lost in spill over.

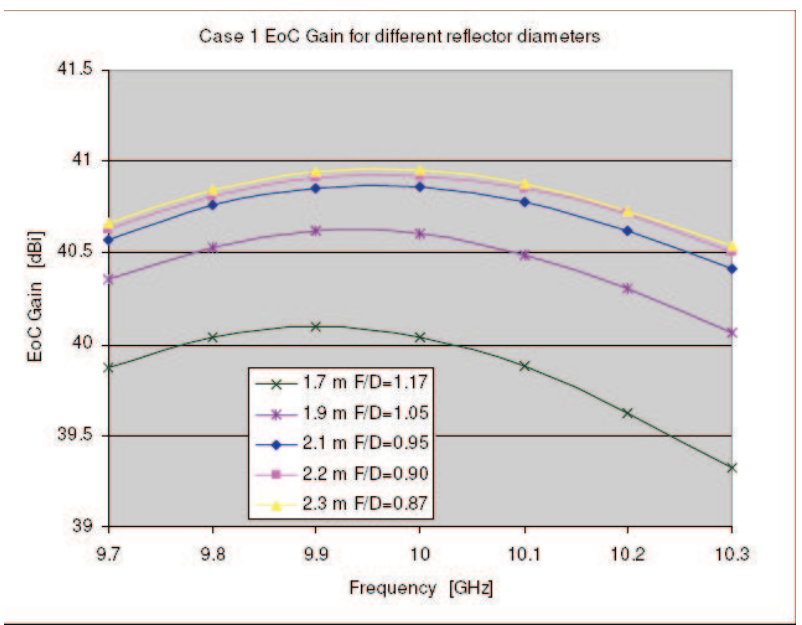

Fig. 6. Edge of coverage gain calculated from the simulated patterns for the best case scenario.

\section{CONCLUSIONS}

A novel strategy has been presented to design multi-beam reflector antenna system based on the excitation of a couple of leaky waves by covering the focal plane array with a single thin dielectric layer and tuning the array design to maximize their positive effect. In the worst case scenario of neighboring co-frequency and co-polarized beams an increase of the $G_{e o c}$ of $1 \mathrm{~dB}$ over a $6 \% \mathrm{BW}$ with respect to the standard free space designs could be obtained. In the scenario of a multi beam system for a telecommunication satellite with four channels an edge of coverage increase larger than $1.7 \mathrm{~dB}$ has been shown over a $3 \%$ BW.

\section{REFERENCES}

[1] S. K. Rao, "Design and analysis of multiple-beam reflector," IEEE Antennas and Propagation Magazine, vol. 41, pp. 53-59, Aug. 1999.

[2] G. V. Trentini, "Partially reflecting sheet arrays," IEEE Antennas and Propagation Magazine, vol. 4, no. 4, pp. 666-671, Oct 1956.

[3] D. Jackson, A. A. Oliner, and A. Ip, "Leaky wave propagation and radiation for a narrow-beam multiple layer dielectric structure," IEEE Transactions on Antennas and Propagation, vol. 41, no. 3, pp. 344-348, March 1993.

[4] C. A. Balanis, Antenna Theory: Analysis and Design. New Jersey: Wiley Interscience, 2005.

[5] R. Gardelli, M. Albani, and F. Capolino, "Array thinning by using a fabry perot cavity for gain enhancement," IEEE Transactions on Antennas and Propagation, vol. 54, no. 7, pp. 1979-1990, July 2006.

[6] D. Jackson and A. A. Oliner, "A leaky-wave analysis of the highgain printed antenna configuration," IEEE Transactions on Antennas and Propagation, vol. 36, no. 7, pp. 905-909, July 1988.

[7] M. Qiu and G. Eleftheriades, "A reduced surface-wave twin arc-slot antenna element on electrically thick substrates," IEEE Microwave Wireless Components Lett., pp. 459-461, Nov. 2001. 